\title{
An Operational Model for the Prediction of Jet Blast
}

\author{
Paul E. Slaboch ${ }^{1}$ \\ John A. Volpe National Transportation Systems Center, Cambridge, MA, 02142
}

\begin{abstract}
This paper presents an operational model for the prediction of jet blast. The model was developed based upon three modules including a jet exhaust model, jet centerline decay model and aircraft motion model. The final analysis was compared with data acquired during a jet blast study conducted by the Volpe Center in 1999. The current analysis closely matched the data from the 1999 test. The analysis was then used to predict the jet blast evolution from aircraft that have been introduced since 1999, including the Boeing 777300ER. The result of this analysis is a tool that can be used to help provide insight to operating procedure designs where jet blast concerns may arise.
\end{abstract}

\section{Introduction}

$\mathrm{J}^{\mathrm{ET}}$ ET blast is the term in air traffic control referring to the plume of hot and high velocity gas emitted from the exhaust of a jet engine particularly on or before takeoff. While it has historically been considered a part of overall wake turbulence behind aircraft, it is not affiliated or related to the wing tip or wake vortices. This view of jet blast was particularly prevalent in the early days of large jet transport aircraft ${ }^{1}$. It is a separate category of wake turbulence and is a typical concern for intersecting runway operations where arriving aircraft may be adversely affected by the jet blast of the departing aircraft at the intersecting runway crossing point.

A jet blast hazard has two main aspects: magnitude and affected area. The description of the hazard concern can be graphically illustrated in Fig. 1 from Zhang, et al. ${ }^{2}$ The present study is concerned with the magnitude only and does not attempt to generalize the affected area aspect of the hazard. The magnitude of the jet blast from an aircraft is a function of the engines installed rather than of the aircraft, though there is a general correlation between aircraft size and maximum thrust per engine. The prevalent view in the air transportation community that the largest aircraft have the largest jet blast is not completely correct and rather it should be stated that the engine with the highest thrust rating has the largest jet blast. This leads to, for instance, the Boeing 777-300ER, otherwise known as the B773 or the $777 \mathrm{~W}$ respectively in the Federal Aviation Administration (FAA) and International Civil Aviation Organization (ICAO) type designations, having a greater jet blast magnitude than the Boeing 747-400 (B744) or the Airbus 380-800 (A388). Currently, the largest commercial engine, in terms of both physical size and thrust output, the General Electric GE90-115B, can be found on the B773/777W. However, the larger aircraft such as A388, with four engines, will have a larger effective jet blast area while having lower peak blast velocities, which should have a lesser impact on airport operations.

The amount of available literature devoted to the measurement and analysis of the jet blast phenomenon is surprisingly small. Specifically, there are very few experimental studies that have been completed regarding jet blast of full scale aircraft with the bulk of this work being performed in the $1970 \mathrm{~s}^{3-5}$. The results of these early efforts did not arrive at a consistent policy on how to meaningfully evaluate or apply jet blast rules operationally. Due to this lack of consistent policy, many airports treated jet blast with traditional wake vortex separation rules. These separations assured the safety of operations but at the cost of capacity, as jet blast is observed to dissipate faster than wake vortices. A noteworthy exception from the aforementioned standard treatment of the jet blast related operational rule has been that of John F. Kennedy International Airport's (JFK) 31L/4R intersecting runway operation, where a dedicated measurement ${ }^{6}$ and analysis of the data in the early 2000 s led to a specific local rule change in the jet blast separation standard. Additional description of this test is highlighted in section III.

The current resurgence of interest in jet blast was motivated again by JFK, due to its taxiway extension and reconfiguration from 2009-2010. As part of the extension, taxiway YA was extended to connect to RWY 22R 500ft to the east of the RWY 31R centerline. This reconfigured intersection geometry caused concern about the possibility of jet blast creating a hazard interfering with normal operations, particularly from newer Heavy and Jumbo aircraft equipped with modern high thrust engines since the 1999 test. This study presents a generalized

${ }^{1}$ Aerospace Engineer, Aircraft Wakes and Weather Division, 55 Broadway, AIAA Member 


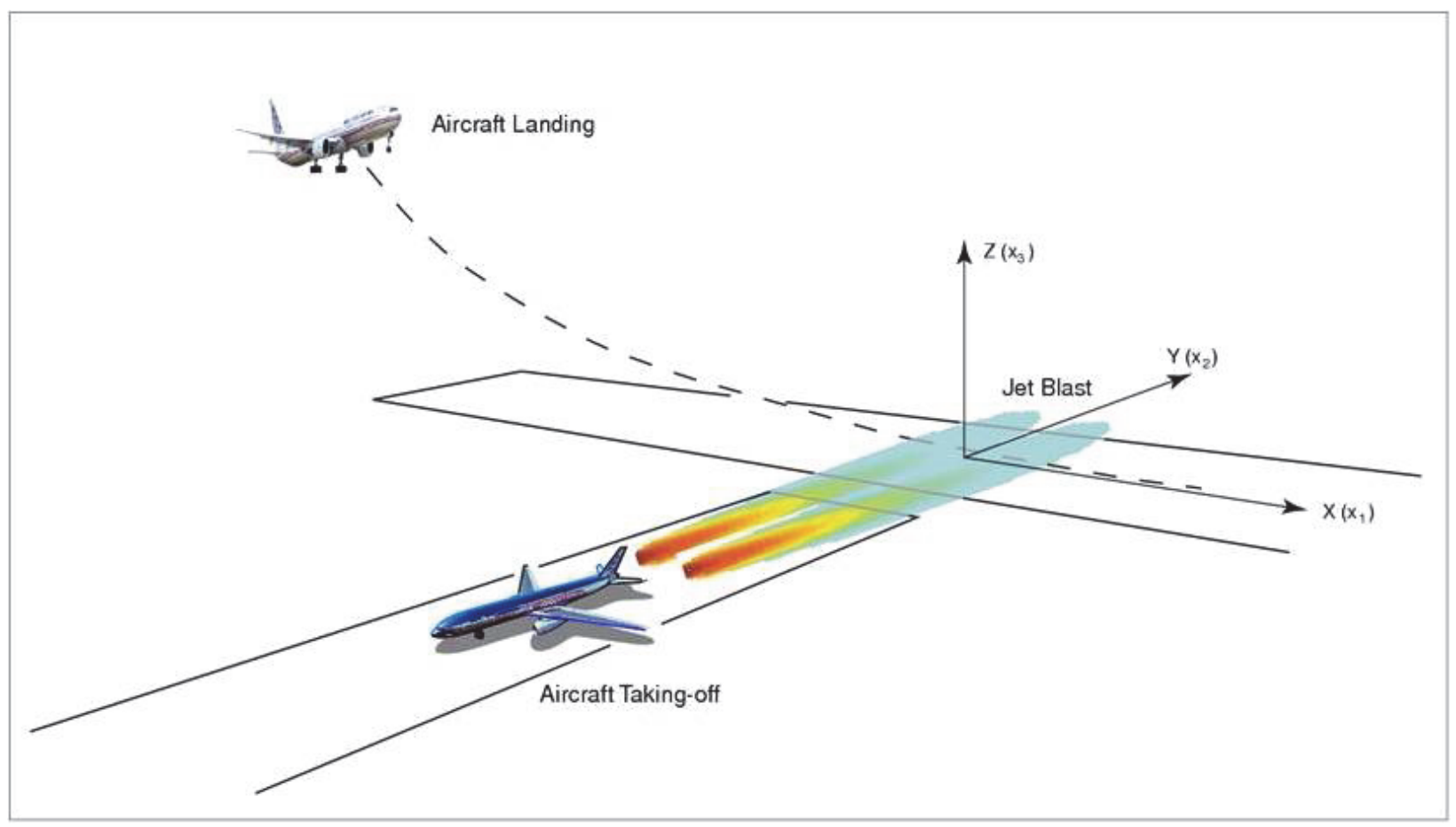

Fig 1. Schematic of jet blast hazard behind departing aircraft from [2]

method for recommending the separation behind any given jet blast producing aircraft at any known fixed distance. The method can be used for any airport geometry in any operational circumstance that may arise from airport reconfigurations or introduction of new aircraft into the fleet.

\section{Methodology}

The methodology used in this study combines models of various aspects of the departing aircraft and operational interest of a specific airport runway geometry. For a given geometry and operation, three aspects of the departing aircraft must be known or modeled in some fashion:

1. Engine exhaust characteristics (initial conditions of jet for calculation of velocity decay)

2. Downstream engine exhaust maximum velocity decay

3. Aircraft motion on departure

All three of these must be known in order to effectively predict the time history of maximum jet blast velocity decay at a fixed location in space.

The methodology to determine the required jet blast separation behind a departing aircraft begins with the engine exhaust characteristics and aircraft parameters, along with the desired operation. All of these are inputs into the engine maximum velocity decay model that has the jet blast magnitude as a function of time (thus translational operationally to a separation distance) as its output. The aircraft parameters are used as inputs to the aircraft motion model while the desired operation is necessary to determine the specific airport geometry in question.

A flow chart of the methodology to determine the required separation behind a given departing aircraft is shown in Fig. 2. An acceptable gust threshold is necessary to determine the required separation for a given arrival aircraft. In [2] and [6], the threshold is chosen to be 4 kts, i.e., 4 kts above ambient is an acceptable crosswind gust for most aircraft. The $4 \mathrm{kt}$ threshold was selected because it is the additional crosswind currently experienced behind an idling B747-400 during normal operations. However, if the method is to be applied to a specific aircraft pair, the required separation can be customized for the arrival aircraft using this threshold parameter depending on the acceptability of the threshold from the stakeholder perspectives.

The various pieces of the methodology will be discussed in reverse order so that the requirements of each section will be clearly laid out. It is difficult to discuss the engine exhaust characteristics before knowing which are 


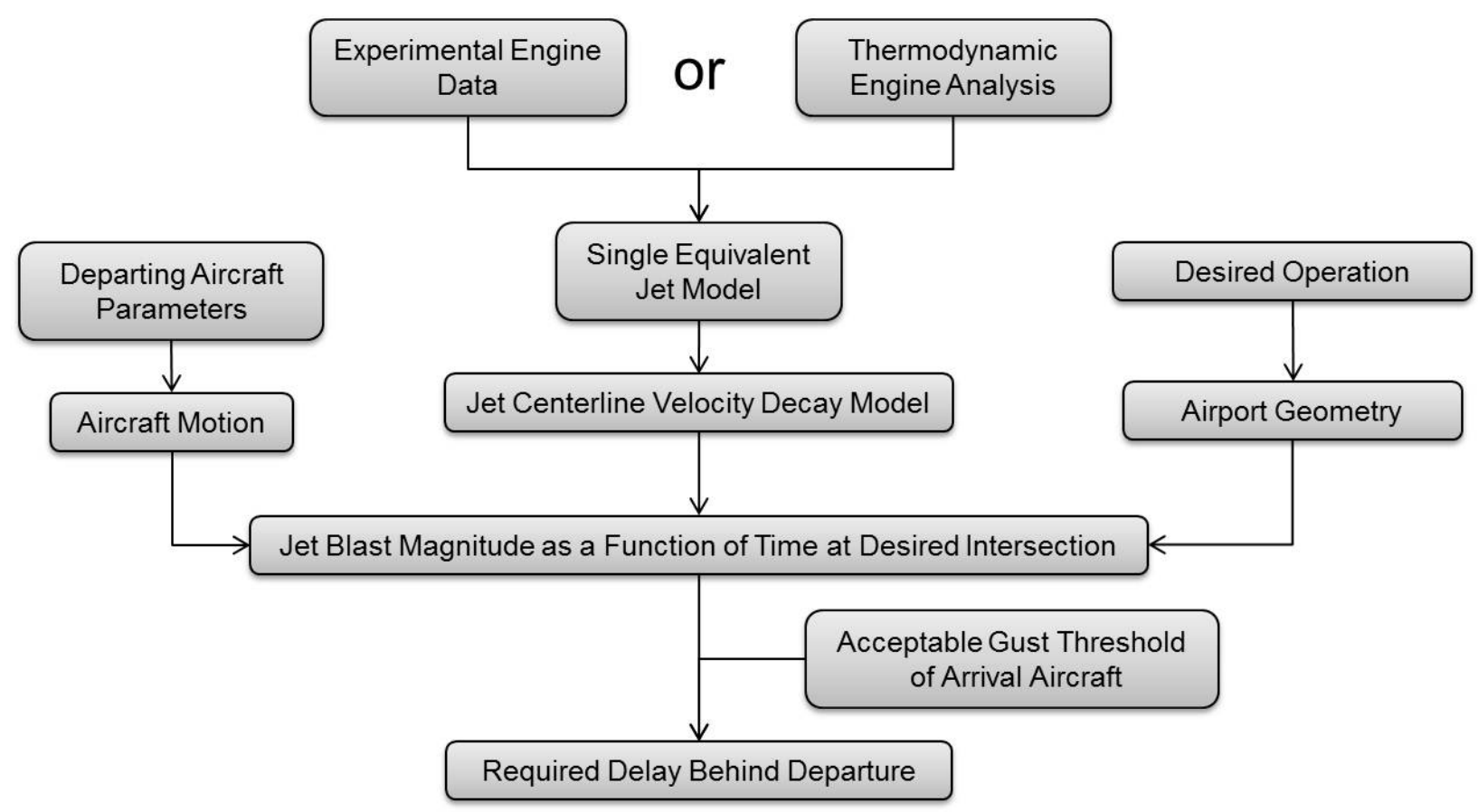

Fig. 2. Flow chart of methodology to determine the required delay behind departing aircraft.

necessary for the next step. Therefore, the explanation of the methodology will begin with the jet blast magnitude as a function of time and look at each branch leading to that junction individually.

\section{A. Jet Blast Magnitude as a Function of Time}

The goal of the methodology is to determine a required safe separation behind a departing aircraft with a second aircraft arriving on an intersecting runway. This is the input that air traffic controllers need to safely separate aircraft on arrival and departure. Before a suitable delay can be determined, it is necessary to know what gusts are acceptable to the arriving aircraft. The jet blast experienced by the arriving aircraft in an intersecting runway geometry is a cross-wind gust. An acceptable gust must be determined, however, a generalized threshold will be assumed for this methodology.

The safe separation time/distance behind a departure is determined from the jet blast magnitude as a function of time at the specific distance behind the start of the departure where the arrival will pass through the blast. A different jet blast magnitude vs. time curve can be constructed for any given distance downstream of the departing aircraft. The required separation is then found by determining the time at which the jet blast magnitude has decayed to the acceptable threshold value. This is a relatively straightforward process.

Three inputs are necessary to determine the jet blast magnitude as a function of time. They are:

1. The operational geometry in question

2. The aircraft position and motion as a function of time

3. The engine maximum velocity decay as a function of distance behind the engine

The operational geometry sets the distance behind the departure that the arrival will pass. The engine maximum velocity decay is given as a function of distance behind the engine and does not change with time. The motion of the aircraft as a function of time determines how far away the departing aircraft is from where the arrival will be. Once the location of the aircraft is known at a given time, the distance from it to the arrival path can be used to determine the velocity from the engine decay curve. All three components are necessary in order to properly determine the jet blast magnitude as a function of time. In the following sections, all three inputs to the jet blast magnitude as a function of time will be discussed. 


\section{B. Engine Exhaust Characteristics}

\section{Engine Maximum Velocity Decay Model}

The engine maximum velocity decay model is based upon a single compressible free jet. Witze ${ }^{7}$ developed a centerline decay model with an exponential decay that is applicable over a wide range of both sub- and supersonic jets. The expression for the jet centerline velocity is given as

$$
\bar{u}_{c}(\bar{x})=1-\exp \left(\frac{-1}{\kappa \bar{x}\left(\bar{\rho}_{e}\right)^{0.5}-X_{c}}\right)
$$

where $\bar{u}_{c}$ is the centerline velocity as a function of downstream coordinate $\bar{x}, \kappa$ is a proportionality constant, $\bar{\rho}_{e}$ density ratio between the external and jet exit flow and $X_{c}$ is non-dimensional correlation parameter core length. The centerline velocity is normalized by the peak core velocity. The core length parameter $X_{c}$ was determined by Kleinstein ${ }^{8}$ to have a universal value of 0.70 . The value of the proportionality constant is determined by the relationship

$$
\kappa=0.08\left(1-0.16 M_{j}\right)\left(\bar{\rho}_{e}\right)^{-0.22}
$$

where $M_{j}$ is the jet exhaust Mach number. This relationship was found to be well correlated with data and is therefore adopted in the current study.

The previous equations give the centerline decay of a single compressible free jet with good agreement to experimental data as shown by Witze ${ }^{7}$. However, this model assumes it is a single jet (representative of turbojet engines), not the co-axial jets that arise from the high bypass turbofan engines installed on commercial transport aircraft. Another model is necessary to reduce the coannular jets to a single jet. This model will be discussed in the following section.

\section{Generating Inputs to Centerline Decay Model}

It is necessary to reduce the coannular flow of modern high bypass turbofan engines to a single equivalent jet that can be used in the velocity decay model discussed above. The jet exit velocity, density and radius are all necessary inputs to the centerline velocity decay model. The engine exhaust characteristics of the departing aircraft can be obtained in a number of different ways. The most direct and reliable method of obtaining the required characteristics is to measure them directly from a production engine. However, this is generally a difficult task to accomplish.

An alternative estimate of the exhaust characteristics is obtained from a thermodynamic analysis of a turbofan jet engine. Many engine manufactures have made public the fan pressure ratios, overall compression ratios, fan diameters and bypass ratios. Using these inputs and reasonable assumptions about thermodynamic efficiency, an estimate of the necessary parameters can be determined. An engine analysis like that found in Mattingly ${ }^{9}$ or Oates ${ }^{10}$ would be sufficient to obtain all of the necessary details of the exit flows of both the bypass and core. These two flows must then be combined into a single equivalent jet (SEJ) to be used in the centerline decay model that requires only a single, compressible free jet.

The SEJ concept has been used in the jet acoustics community for over 30 years ${ }^{11}$. There are at least two different approaches for calculating a SEJ: assume a constant area or constant enthalpy. The constant area procedure was used by Tanna ${ }^{12}$ and employed a constant nozzle exit area when combining the jets. Zaman and Dahl ${ }^{11}$ developed a constant enthalpy procedure that allows the SEJ exit area to be larger or smaller than the combined area of the two coannular flows that are input into the SEJ, and is considered to be a more physically meaningful conservation criterion than the more traditional constant area calculation. The constant enthalpy procedure requires the simultaneous solution of four equations with four unknowns. These four parameters, the equivalent density, velocity, area and static temperature, are all that is necessary to fully define the single equivalent jet. The four equations in four unknowns are repeated here for completeness from [11].

$$
\begin{gathered}
\rho_{1} U_{1} A_{1}+\rho_{2} U_{2} A_{2}=\rho_{e q} U_{e q} A_{e q} \\
\rho_{1} U_{1}^{2} A_{1}+\rho_{2} U_{2}^{2} A_{2}=\rho_{e q} U_{e q}^{2} A_{e q} \\
T_{a}=t_{e q}+\frac{U_{e q}^{2}}{2 C_{p}}=t_{1}+\frac{U_{1}^{2}}{2 C_{p}}=t_{2}+\frac{U_{2}^{2}}{2 C_{p}}
\end{gathered}
$$




$$
p_{a}=\rho_{e q} \boldsymbol{R} t_{e q}=\rho_{1} \boldsymbol{R} t_{1}=\rho_{2} \boldsymbol{R} t_{2}
$$

The subscripts 1 and 2 denote the core and bypass jets, respectfully, and the subscript "eq" denotes the single equivalent jet parameters to be used as input to equations (1) and (2). Lower case variables represent static quantities while capitalized variables represent total quantities and the subscript " $a$ " stands for ambient. Equation (3) is reduction of the conservation of mass, while Eq. (4) represents the conservation of momentum and Eq. (5) is definition of total temperature which is constant everywhere for the current problem. Equation (6) is simply the equation of state with $\boldsymbol{R}$ denoting the gas constant and noting that the static pressure is constant as well. The output from these four equations can be used as an input into the centerline decay model of a free compressible jet discussed above.

\section{Aircraft Motion}

The motion of the aircraft is an important aspect to properly determine both the position of the aircraft and time at which the jet blast has fallen below the threshold. There are two methods for determining the aircraft motion. The first is a basic summation of forces acting on the aircraft. The more forces that can be characterized, the better the aircraft motion model will be. In general, it is necessary to know the total thrust output from all engines along with the weight of the aircraft and an estimate of pressure, skin friction and rolling friction drag. The summation of these forces will yield an acceleration that can be integrated with respect to time to give velocity and distance from the starting point.

Another model that can used to determine the aircraft motion on takeoff, and used in the current analysis, was developed in the SAE-AIR-1845 document ${ }^{13}$, "Procedure for the Calculation of Airplane Noise in the Vicinity of Airports." Appendix A of this document, released in 1986, developed a system of equations used to calculate the noise pollution of aircraft, and in the process also developed equations regarding aircraft motion on taxi and takeoff. The models developed by the SAE have been used extensively and represent one of the best methods to systematically determine the takeoff speeds and accelerations of various aircraft. From the equations in Appendix A of SAE-AIR- $1845^{13}$, the aircraft acceleration can be calculated as

$$
a=\frac{C_{f}^{2} N\left(\frac{F_{n}}{\delta}\right)}{2 B_{f}\left(\frac{W}{\delta}\right)}
$$

where $a$ is the acceleration, $C_{f}$ is the flap setting dependent takeoff speed coefficient, $N$ is the number of engines, $\left(\frac{F_{n}}{\delta}\right)$ is the corrected takeoff thrust, $B_{f}$ is the flap setting dependent ground-roll coefficient, $W$ is the takeoff weight and $\delta$ is the pressure ratio at the airport. The corrected takeoff thrust is determined from

$$
\left(\frac{F_{n}}{\delta}\right)=E+(F * v)+\left(G_{a} * h\right)+\left(G_{b} * h^{2}\right)+\left(H * T_{c}\right)
$$

where $v$ is the calibrated airspeed, $h$ is the pressure altitude, $T_{c}$ is the temperature (in deg C) at the aircraft and $E, F, G_{a}, G_{b}$ and $H$ are regression coefficients that depend on power state and temperature state of the aircraft and engine. The regression coefficients are available through either the FAA's Integrated Noise Model (INM) software ${ }^{14}$ or through EUROCONTROL Experimental Centre's Aircraft Noise and Performance (ANP) Database ${ }^{15}$. These two data sources contain all of the relevant information necessary to use the two relations above and determine the acceleration of the aircraft during the takeoff roll.

\section{Airport Geometry/Desired Operation}

The airport geometry and desired operation to be investigated are necessary to determine the distance between the point of departure and the centerline of the perpendicular arrival runway. Each intersection and possible operation has its own operating limitations and will subsequently have separate jet blast requirements. However, since the geometry of the airport and operation is set, this portion of the methodology is determined by the user and is included here only for completeness. 


\section{Validation of Methodology}

\section{A. Jet Blast Test Program at JFK}

In 1999, the Port Authority of New York and New Jersey (PANYNJ) requested an investigation of potential jet blast interference at a particular runway intersection at JFK. The Volpe Center was tasked to complete a jet blast data collection campaign and analyze the results for $\mathrm{JFK}^{6}$.

The runway intersection of interest had a spacing of $760 \mathrm{ft}$ behind the departing aircraft. Due to the fact that data cannot be acquired on an active runway for the specific geometry of interest by JFK, an array of anemometers was erected $760 \mathrm{ft}$ behind the departure location on RWY 13R. The anemometer array consisted of 7 poles, each $50 \mathrm{ft}$ tall with 8 propeller anemometers per pole. The anemometers were spaced $5 \mathrm{ft}$ apart going up the pole, starting at 10 $\mathrm{ft}$ from the ground. The poles were spaced $55 \mathrm{ft}$ apart for a total area of coverage of $+/-165 \mathrm{ft}$ to either side of the runway. Anemometers for measuring the crosswind and vertical winds were installed on the center and end poles. The anemometer data was sampled at $10 \mathrm{~Hz}$. The area of coverage was selected as a safety critical area behind the departing aircraft and the goal of this effort was not to capture the full extent of the jet blast.

A video camera was used to record each departure and determine the aircraft type. The time series data from the anemometers were matched up using the time stamp of the video in post-processing. The test focused solely on jet blast behind Heavy aircraft, defined as having a maximum certificated takeoff weight of 255,000 lbs at the time of the study. A total of 636 departure jet blasts were recorded and analyzed.

The data were analyzed to determine the time required for the jet blast to subside to either $4 \mathrm{kt}$ or $10 \mathrm{kt}$ above the ambient wind conditions. The $4 \mathrm{kt}$ and $10 \mathrm{kt}$ thresholds were selected as the expected additional cross wind from and idling B744 and maximum allowable crosswind, respectively. It was found that $100 \%$ of cases decayed to within $10 \mathrm{kts}$ of ambient within 50 seconds and to within $4 \mathrm{kt}$ of ambient within $70 \mathrm{sec}$. The mean jet blast duration to decay to the $4 \mathrm{kt}$ threshold for all aircraft was found to be approximately 38 seconds. The full details of this study may be found in the report ${ }^{6}$ and will not be further described here.

\section{B. Re-examination of 1999 JFK Jet Blast Data}

The jet blast data acquired in 1999 for the JFK jet blast campaign was re-examined in order to apply it to the new geometries of interest at JFK. Specifically, the data were reprocessed using a more automated method that did not rely on manual intervention to determine the jet blast decay times. An algorithm was developed to determine the jet blast decay automatically from the time series anemometer data. Each time series had been truncated to include the jet blast from a specific departure and was labeled by aircraft type. The full array of 56 anemometers was analyzed to look for the peak velocity amongst all anemometers at each time. A 5 second moving average was used to smooth the data of the peak velocities.

During the reprocessing, it was noticed that the peak velocity recorded in the majority of jet blast cases occurred on one of the extreme poles and anemometers of the array, i.e., the topmost anemometer on the furthest pole. Figure 3 shows contours of axial velocity in knots over the area of the anemometer array for the time of maximum jet blast velocity behind a B744. It is clear from the image that most of the array is simply recording the background winds while only the rightmost anemometers recorded the jet blast velocity. No worst-case jet blast information can be obtained from an analysis of this type of data as the full jet blast was not captured by the anemometer array. With only a portion of the jet blast recorded, it is likely that the true peak velocity will fall somewhere outside of the array and the decay to any threshold will be artificially truncated. It is important to note here that the original purpose of the 1999 JFK study was not to capture the maximum jet blast velocity, but rather to monitor and record the jet blast observed in a well-defined safety corridor directly behind a departing aircraft.

For model development and validation purposes, the jet blast duration should be determined based upon only those cases where the maximum jet blast velocity was clearly captured in the region covered by the array of anemometers. Figure 4 shows another jet blast behind a B744 at approximately the same decay time, however, the jet blast can be seen to be fully captured over the area of the array. In this particular instance, 2 distinct jets can be seen centered approximately $150 \mathrm{ft}$ apart. A careful examination of Fig. 4 reveals that the contours are closed for the jet signature on the right while the signature on the left has drifted towards the top of the array and only the centermost contour was able to close. This closure is evidence that the maximum jet blast velocity has been captured and can be tracked for the duration of the departure. Only those cases that exhibited behavior similar to that of Fig. 4 were used in the reprocessing of the JFK data. Specifically, the peak jet blast velocity was forced to be found inclusively between poles 3 and 5 and between anemometer 3 and 6 . This limits the initial location of the peak and insures that only the longest lasting of the 636 cases will survive and will yield the most accurate jet blast decay results, as well as providing a dataset for modeling jet blast evolution without the consideration of a specific safety 


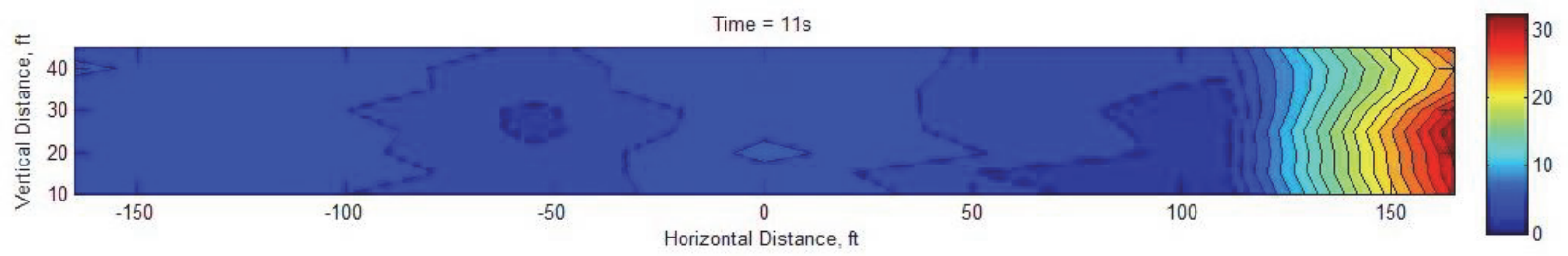

Fig. 3. Contours of axial velocity at time of maximum recorded jet blast behind a $B 744$ departure. Colors represent absolute axial velocity in kts. Only the rightmost pole captured any part of the jet blast.

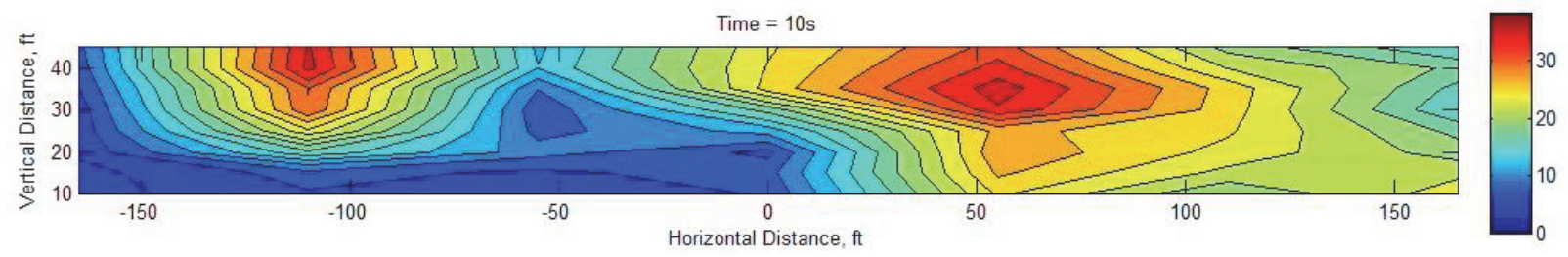

Fig. 4. Contours of axial velocity at time of maximum recorded jet blast behind a B744 departure. Colors represent absolute axial velocity in kts. Two distinct jet signatures can be observed with approximately $150 \mathrm{ft}$ separation.

corridor to be monitored, as jet blast drifts with ambient wind. Applying these restrictions on the positions of the jet blast peak velocity greatly reduced the number of jet blast departures usable for analysis from 636 to 129 . The majority of those cases are for B767 aircraft (100 of the 129 total cases).

The 129 cases identified as suitable for modeling purposes were processed according to a new algorithm that removed the need for the more labor intensive manual analysis and processed the data in a more objective as well as consistent fashion. One of the most important aspects of this analysis is the determination of the ambient winds. The ambient winds were determined as the average wind over the 15 seconds preceding the departure.

The start of the jet blast "track" was set to $5 \mathrm{sec}$ before the time of the peak velocity at any point in the array. All of the peak velocities were then aligned in time and the statistics of the jet blast program were able to be calculated based upon these times. The tracks were terminated once the maximum velocity at any point in the array fell below the threshold of interest, either $10 \mathrm{kt}$ or $4 \mathrm{kt}$.

The 129 tracks were each determined for both a $10 \mathrm{kt}$ and $4 \mathrm{kt}$ threshold. For a $10 \mathrm{kt}$ threshold, the maximum jet blast duration was found to be $42 \mathrm{sec}$. The mean jet blast duration to $10 \mathrm{kt}$ was found to be approximately 27 seconds. For a $4 \mathrm{kt}$ threshold, the maximum duration was found to be 58 seconds with the mean being approximately 40 seconds.

\section{Comparison of Model to JFK Data}

The purpose of this study was to determine a validated methodology to be applied in an operational context at any airport that has need for a jet blast analysis. It is also necessary to able to apply the current methodology to aircraft that were not in service at the time of the 1999 JFK study, specifically, the A380 or/and B777-ER. The methodology will be validated using the data from the 1999 JFK study.

Because of the operational nature of the use of this model and methodology, it is desired to allow for a factor of safety. A 95\% confidence limit based upon the standard deviation of the experimental data was added to the predictions using the methodology prescribed in the previous section. The following figures showing a comparison of the model to the data will show both the deterministic mean of the jet blast, as well as the $95 \%$ confidence limit in a conservative sense only, i.e. only the upper $95 \%$ confidence limit will be shown.

The most appropriate manner to examine the jet blast decay characteristics from many different aircraft and engines is non-dimensionally. The peak jet blast velocity will be used as a velocity scale with the nozzle radius of the engine being the correct length scale of the problem. These two combined parameters provide the appropriate time scale of $r / u_{\text {peak }}$. All of the jet blast tracks acquired in the JFK study were non-dimensionalized in this manner and are compared to a non-dimensional model of jet blast using the current methodology. The comparison can be seen in Fig. 5.

The non-dimensional comparison of the jet blast data with the current methodology shows good agreement between the two after a non-dimensional time of approximately 200. Before that time, the current method over predicts the jet blast magnitude by a significant amount. The current method goes through an inflection point near a 


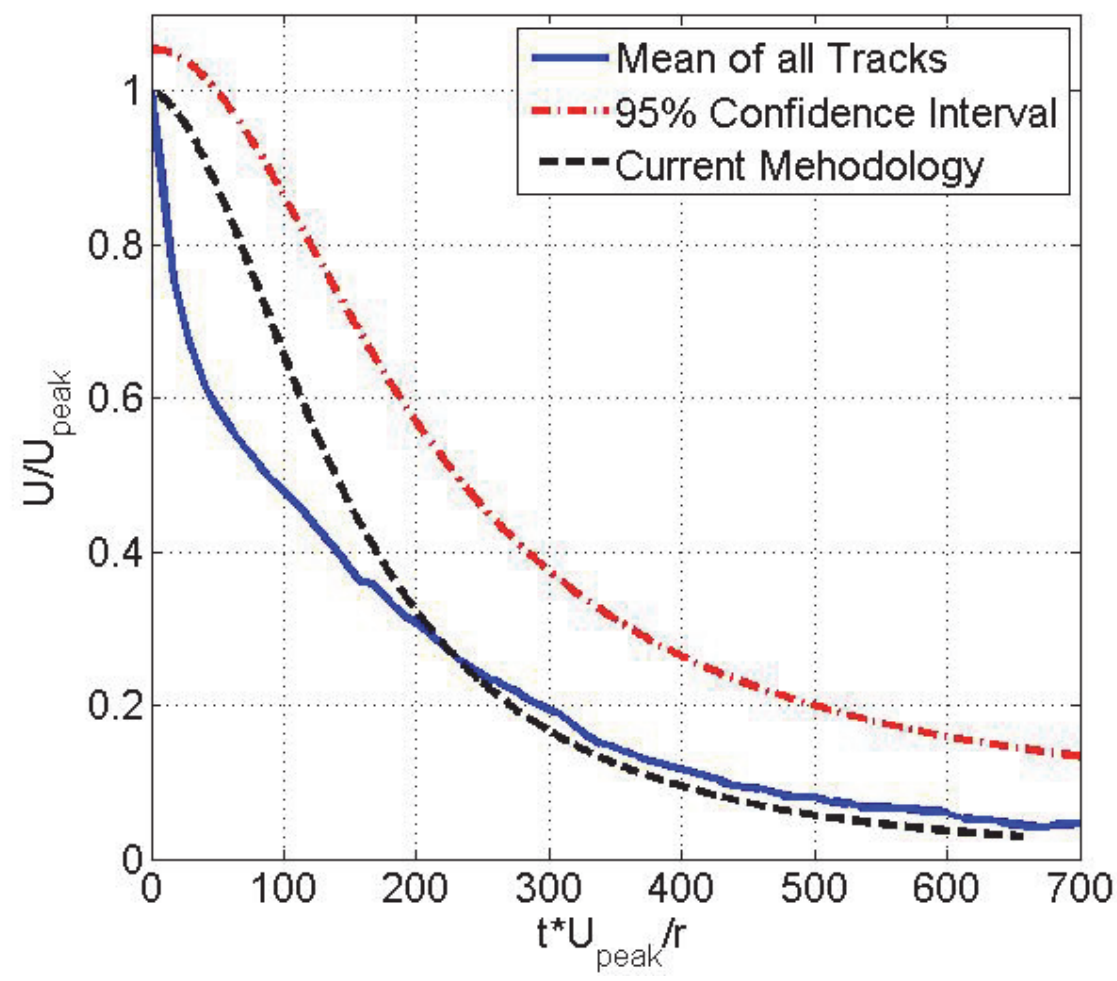

Fig. 5. Comparison of JFK experimental jet blast data to current methodology.

non-dimensional time of 100 while the jet blast data exhibits no inflection points at all. However, in an operational context in which a conservative answer is sought, and over prediction of the jet blast magnitude is acceptable. It should also be noted that the $95 \%$ confidence limit gives a very conservative estimate of the jet blast decay and should yield a safe and effective air traffic control strategy. This conservative estimate of the jet blast decay allows the expanded use of the methodology for aircraft and geometries that were not in service in 1999.

It is also notable that the current method, given the correct inputs, does not rely on any arbitrary fitting constants to tune the model to a given aircraft or engine, beyond those found in the aircraft motion model. Various other jet blast models rely on a fitting parameter, i.e. Zhang et. $\mathrm{Al}^{2}$.

\section{Comparison to Airport Planning Documents}

The airport planning documents published by the aircraft manufacturer ${ }^{16-20}$ contains a section entitled "Jet Engine Wake and Noise Data." This section reports contours of velocity behind the aircraft for different thrust configurations, including idle, breakaway and take-off thrust. The contours are generally described in the planning document as being calculated from Navier-Stokes computation at sea level on a standard day with no wind and all engines running at maximum thrust for take-off. No further insight is known about the nature of the information contained in the airport planning documents.

The best way to take advantage of this information is to construct an engine thrust velocity decay fit as a function of axial distance from the computation results. A decay model should have the form of $u_{c}=1-\exp \left(1 / x_{c}\right)$. However, it is not entirely reliable to construct such a curve from the coarse velocity contour results represented in the airport planning documents on spatial evolution of the jet exhaust characteristics.

As a point of comparison between the current method and the airport planning documents, the current model was used without the aircraft motion model to determine the engine exhaust velocity at the same distances downstream given in the planning documents for each of 5 engines. Figure 6 shows the ratio of the current model to the planning documents as a function of axial downstream distance. It is interesting to note that the decay rates for all of the aircraft were different in the initial region after the aircraft and then began increasing with distance. This suggests that the airport planning documents provide a very conservative estimate of the jet blast, relative to the current methodology. 


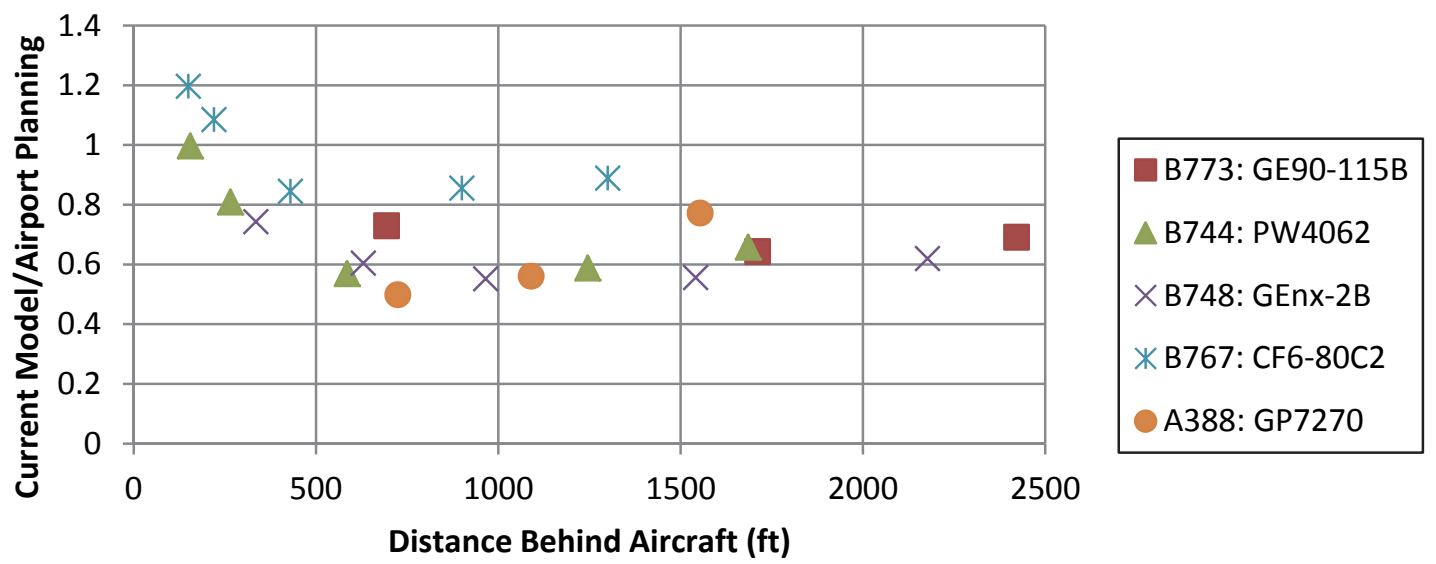

Fig. 6. Ratio of current model jet blast magnitude to airport planning document as a function of axial downstream distance.

\section{Example Using Methodology for New Taxiway Construction}

This section will describe the process for using the current method to determine an acceptable jet blast avoidance air traffic control strategy using the results that were benchmarked against data acquired at a distance of $760 \mathrm{ft}$ behind the departure.

Consider an airport that is constructing a new taxiway that will allow aircraft to depart only $500 \mathrm{ft}$ in front of the centerline of a perpendicular runway which used for arrivals. Using the methodology described in previous sections, the jet blast duration from various engines can be determined at $500 \mathrm{ft}$ by inputting that distance into the methodology. The majority of steps involved in the methodology are constant for a given engine and aircraft and would only need to be determined once, at which point they can be used for any distance behind the aircraft.

A $4 \mathrm{kt}$ threshold will be assumed here for simplicity and consistency with results already obtained. As of the completion of this study, the largest production engine in use on a commercial aircraft is the GE90-115B engine that is installed on the B777-300ER. This engine will be used as the baseline case.

Applying the methodology using either experimental data or the appropriate thermodynamic analysis of the engine will yield all of the inputs into the centerline decay model. Adding these inputs with the airport geometry of $500 \mathrm{ft}$ separation behind the departure and the aircraft motion model of a B773ER yields the dimensional predicted jet blast shown in Figure 7.

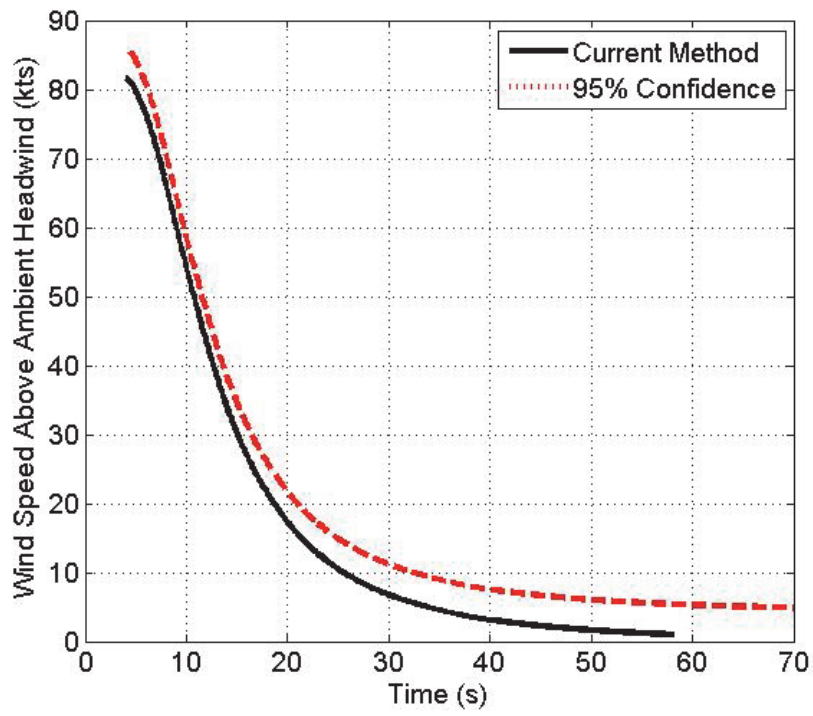

Fig. 7. Predicted jet blast decay $500 \mathrm{ft}$ behind B777-300ER departure. 
Table 1 Representative approach speeds and time to various distances

\begin{tabular}{ccccc}
\hline \hline Approach Speed, kts & Time to $3.5 \mathrm{~nm}, \mathrm{~s}$ & Time to $3.0 \mathrm{~nm}, \mathrm{~s}$ & Time to $2.5 \mathrm{~nm}, \mathrm{~s}$ & Time to 2.0 nm, $\mathrm{s}$ \\
\hline 150 & 83 & 72 & 60 & 48 \\
145 & 87 & 74 & 62 & 50 \\
140 & 90 & 77 & 64 & 52 \\
135 & 93 & 80 & 67 & 53 \\
130 & 97 & 83 & 69 & 55 \\
125 & 100 & 86 & 71 & 57 \\
120 & 104 & 89 & 74 & 59 \\
\hline \hline
\end{tabular}

The deterministic mean of the current methodology gives a time of $37 \mathrm{sec}$ to reach the $4 \mathrm{kt}$ threshold. However, the $95 \%$ confidence limit, which is only used to be safe and conservative in this operational context, yields a time to the $4 \mathrm{kt}$ threshold of $62 \mathrm{sec}$. In this particular case, the $95 \%$ confidence adds a full $25 \mathrm{sec}$ to the mean jet blast time for safety. The additional $25 \mathrm{sec}$ represents a $67 \%$ increase over the mean time of $37 \mathrm{sec}$. This represents the worst case scenario at $500 \mathrm{ft}$ behind the departure point. All other aircraft will have a smaller peak velocity as well as a shorter jet blast decay time to the $4 \mathrm{kt}$ threshold.

A compilation of the representative approach speeds of various types of aircraft determines that the fastest approach speeds are of the order of $150 \mathrm{kt}$ while smaller aircraft have approach speeds of approximately $120 \mathrm{kt}$. Table 1 shows the time it would take an aircraft at the given approach speed to reach the runway intersection point. These calculations are necessary for air traffic controllers to fully implement the recommendations from a time to a distance based separation. This table shows that the shortest time for any aircraft to land from $2.5 \mathrm{~nm}$ out is $60 \mathrm{sec}$, which is shorter than the maximum time of $62 \mathrm{sec}$ predicted for the B773ER. In this case, a conservative restriction that the arrival aircraft must be at least $3.0 \mathrm{~nm}$, or $72 \mathrm{sec}$, away for the departure to take place would be applied, which leaves a $10 \mathrm{sec}$ buffer between the demise of the jet blast and the shortest anticipated arrival time. This rule can be applied to all aircraft both departing and arriving while maintaining safe operations across the airport.

If the airport in question does not have any scheduled B773ER arrivals or departures, the airport may choose to decrease the distance on final approach from $3.0 \mathrm{~nm}$ down to 2.5 or 2.0, depending and the other aircraft types they are expecting to depart. This allows for the airports to have full control over their ATC operations and also provides great flexibility that is only dependent on aircraft traffic mix.

\section{Summary}

A methodology was presented that allows for the computation of the jet blast characteristics for any given aircraft during departure. The methodology consists of three major parts:

1. Engine exhaust characteristics

2. Exhaust centerline decay model

3. Aircraft motion model

These three parts of the methodology combine to give a full methodology that can be used to determine the jet blast at any given axial distance downstream from the departing aircraft. The final output of the methodology is a time history of jet blast velocity above the ambient wind conditions at a fixed point downstream of the departure point of the aircraft.

The engine exhaust characteristics are the most important input into the centerline decay model. The engine exhaust can be calculated from a full thermodynamic analysis of the engine or obtained directly from experimental data. If both the bypass and core flow fields are solved in the thermodynamic analysis or obtained from experimental data, a Single Equivalent Jet (SEJ) model can be used to provide the proper input into the centerline decay model.

The centerline decay model consists of a 1-D exponential decay model of a free jet into still air. The velocity of the aircraft is taken into account when computing the exit velocity of the jet. The aircraft motion is determined based upon an acceleration developed for airport noise determinations. The aircraft motion model takes into account flap settings, rolling friction and both pressure and friction drag on the aircraft.

The model was validated against a dataset of jet blast recorded at JFK airport in 1999. The model showed excellent agreement with the experimental results. An example was given of a situation in which the model can be used to predict the jet blast characteristics of various types of aircraft for any given airport geometry. 


\section{Acknowledgments}

The author would like to thank Frank Wang and Melanie Soares of the Volpe Center for their helpful discussions regarding the original jet blast study and coannular flows. Thanks also to David Senzig of the Volpe Center for discussions regarding the SAE taxi and takeoff acceleration models. The author would also like to acknowledge Steve Lang, Jeff Tittsworth and Wayne Bryant of the FAA for their support of this project and Tom Bock of the PANYNJ for his permission to use the data from the original JFK jet blast study.

\section{References}

${ }^{1}$ Jones, D. N. "Introduction to Jet-Engine Exhaust and Trailing Vortex Wakes," TR-226, April 1970, Air Weather Service (MAC), USAF, Scott Air Force Base, IL.

${ }^{2}$ Zhang, Y., Rudis, R. P., Wang, F. Y., and Spitzer, E. A., "Simulation of Jet Blast Effect on Landing Aircraft," Air Traffic Control Quarterly, Vol. 9, No. 3, 2001, pp. 211-227.

${ }^{3}$ Carr, J. W. "Surface Velocities and Temperature Changes for C-130, C-141, and C-5A Exhaust Blasts and C-5A Wing-Tip Vortex," AEWES-S-73-61, June 1973, Army Engineer Waterways Experiment Station, Vicksburg, MS.

${ }^{4}$ Christiansen, G. H., "Jet Blast Fence Investigation at John F. Kennedy International Airport," Report Number FAA-RD-75121,1975

${ }^{5}$ Rasch, N., and Walaconis, J Aircraft Jet-Blast Effects at Intersection of Runways 31L-4R, John F. Kennedy International Airport, NAFEC Technical Letter Report, NA-77-70-LR, 1977

${ }^{6}$ Rudis, R. P., Daskalakis, A. C., "Jet Blast Test Program," DOT-VNTSC-RSPA-00-01, Volpe National Transportation Systems Center, Department of Transportation, Cambridge, MA, 2000.

${ }^{7}$ Witze, P. O., "Centerline Velocity Decay of Compressible Free Jets," AIAA Journal, Vol. 12, No. 4, 1974, pp. 417-418.

${ }^{8}$ Kleinstein, G., “An Approximate Solution for the Axisymmetric Jet of a Laminar Compressible Fluid," Quarterly of Applied Mathematics, Vol. 20, No. 1, 1962, pp. 49-59.

${ }^{9}$ Mattingly, J. D., Elements of Gas Turbine Propulsion, McGraw-Hill, Inc., New York, 1996.

${ }^{10}$ Oates, G. C. (ed.), Aerothermodynamics of Gas Turbine and Rocket Propulsion, AIAA Education Series, AIAA, New York, 1997.

${ }^{11}$ Zaman, K. B. M. Q. and Dahl, M. D., "Noise and Spreading of Subsonic Coannular Jets - Comparison with Single Equivalent Jet," AIAA Journal, Vol. 45, No. 11, 2007, pp. 2661-2670.

${ }^{12}$ Tanna, H. K., "Coannular Jets - Are They Really Quiet and Why?,” Journal of Sound and Vibration, Vol. 72, No. 1, 1980, pp. 97-118.

${ }^{13}$ SAE Committee A-21 Aircraft Noise, "Procedure for the Calculation of Airplane Noise in the Vicinity of Airports," SAEAIR-1845, 1986.

${ }^{14}$ INM7.0b, Integrated Noise Model, Software Package, Ver. 7.0b, Federal Aviation Administration, 2009.

${ }^{15}$ Aircraft Noise and Performance Database, ECAC Doc 29 3rd Edition, EUROCONTROL, 2009.

${ }^{16}$ 747-400 Airplane Characteristics for Airport Planning, Boeing Commercial Airplanes, Doc D6-58326-1, 2002, Sect. 6.1.

${ }^{17}$ 747-8 Airplane Characteristics for Airport Planning, Boeing Commercial Airplanes, Doc D6-58326-3, 2008, Sect. 6.1.

${ }^{18} 777-200 \mathrm{LR} /-300 \mathrm{ER} /$-Freighter Airplane Characteristics for Airport Planning, Boeing Commercial Airplanes, Doc D658329-2, 2009, Sect. 6.1.

${ }^{19} 767$ Airplane Characteristics for Airport Planning, Boeing Commercial Airplanes, Doc D6-58328, 2005, Sect. 6.1.

${ }^{20}$ Airbus A380 Airplane Characteristics for Airport Planning, Airbus S.A.S., 2011, Sect. 6-1. 